\title{
How We Do It
}

Vivian K. Harlin, MD, MSPM

Contributing Editor

\section{Teaching Breast Self-Examination in the High School}

We are all familiar with the statistic that one in 15 women will develop breast cancer sometime in her life. Many women's worry about the possibility of breast cancer has become actualized. At present about $95 \%$ of breast cancer is detected by the woman herself; however, these discoveries occur so late that $60 \%$ of those lesions have already spread resulting in a less than favorable prognosis. Upon closer questioning many women acknowledged that the lump was found by a boyfriend or husband. A Gallup survey found that three out of four women who had heard about breast self-examination did not practice it. These women identified their own ignorance of the technique as their reason for inaction. ${ }^{1}$ To reduce the risk of breast cancer women need increased skills and knowledge to do effective breast self-examination.

Effective breast self-examination skills are vital for early detection of breast cancer. Once women know how to do monthly breast self-examinations they find it reassuring to discover they are indeed healthy. Reaching women to teach them these skills, however, is difficult.
A community project was undertaken to incorporate breast self-examination into the curriculum of two high schools in a suburban community. The authors decided to direct their efforts to the high school population because they seemed to be the ideal population for learning these skills. First, they are easily accessible. Second, research has found that good health habits are best established at an early age. ${ }^{2,3}$ Learning this skill early is im. portant because breast cancer can, though rarely, occur in the high school population. Another benefit is that high school students might share this information with older female family members who are at higher risk. In the authors' experience in teaching breast self-examination it seems the younger generation is more comfortable with touching their own bodies and is more easily influenced to practice breast self-examination. Incorporating breast self-examination in the high school curriculum along with other health teaching might have the long range effect of reducing the barriers of fear, ignorance and embarrassment sometimes accompanying this practice. For these reasons the authors firmly believe that the high school population should be exposed to breast self-examination knowledge. Those who are in the education and health fields are faced with a two-pronged challenge. Women need to learn breast examination skills, yet at the same time they need help to reduce the barriers toward practicing what they have learned.

The Wayne County branch of the American Cancer Society found that the public health nurses were the most viable teachers and the high school population, the most appropriate population. In the 1974-1975 school year they began a project to teach breast self-examination to tenth-grade females in Detroit. They chose this grade because of the large number of dropouts in the eleventh grade. They accomplished this task by teaching the breast self-examination content to the public health nurses whose services are utilized by the schools in Detroit. The public health nurses enjoyed teaching this and also reported adult behavior on the part of the students. This program continued in the 19751976 school year. However, as of this writing this program has not yet been evaluated. Thus, we implemented a project in a local high school.

\section{Implementation}

We visited two area high schools of about 3,000 students per school hoping to give a presentation of breast self-examination to their women students. The school nurse in one high school did not give permission for us to teach this information. She had some concerns that we might unduly frighten students about cancer. Thus students in this high school were not taught breast self-examination skills. In the other high school, the school 
nurse was receptive. Since students were being taught about health through physical education classes, we asked the physical education teachers if they would be willing to teach this in their classes. We felt the physical education teachers with whom the students were familiar and who taught some health education would produce less anxiety in the students. These teachers, however, were very uncomfortable with the subject matter. They predicted that their students' responses would be "awful" and "embarrassed." We then decided that the school nurse would teach breast self-examination to students on a voluntary basis during five sessions throughout the school day. These sessions were met with enthusiasm and mature, concerned behavior by both male and female students. One hundred six or $6 \%$ of the female students attended.

Teaching methodology included the American Cancer Society films, deleting the section on coping with mastectomy surgery. This was followed by demonstration and return demonstration of finding masses on the "Betsi" breast model. An informal discussion period was then held where they discussed concerns and per-

I would like more information about:

$\begin{array}{ll}\text {-- High School-Age Students } & N=106 \\ \text { - College-Age Students } & N=20\end{array}$

\begin{abstract}
how to do a breast self-examination.
when to do a breast self-examination.

why to do a breast self-examination.

what to look for when doing a breast

self-examination.
\end{abstract}

ceptions. Through a questionnaire (106 were completed) we asked what high school students considered the preferable age to learn this skill, where they were currently learning about breast self-examination, and whom they would prefer to teach them about this. Also, we identified gaps of knowledge these students had that might prevent them from doing breast self-examination. The authors also asked with whom they would share the in. formation they had gained.

We felt we needed to test the validity of the high school students' responses and to discover at what age adults would find it acceptable to teach breast selfexamination skills. In an effort to reach adults, our breast selfexamination presentation was incorporated into a general health fair at a state university of 17,000 students. One hundred twenty posters were distributed to all departments within the university, advertising the health fair. There was minimal response; forty men and women $(1.5 \%)$ attended the breast self-examination session. Twenty, including three men, voluntarily filled out a questionnaire.

The same teaching methodology was utilized in the college group but with an added opportunity for women to learn to examine their own breasts privately with a nurse. Ten participants accepted this offer and were given a "road map" of their own breasts. They learned to inspect and palpate themselves, and to identify which parts were bones or felt like "cottage cheese," like "waves," or like "grains of sand."

\section{Results}

Two groups were compared: high school students $14-18$ years of age, and college-age students, the women generally being $18-25$ years of age. Those in the collegeage group were usually single and college graduates. In the questionnaire which was given after the teaching session, the women were asked what additional information they would need to practice effective breast self-examination. Sixty-five percent of the high school-age students and $45 \%$ of the college-age students felt they had enough information to practice breast selfexamination, but $45 \%$ of the high school-age group and 55\% of the college-age group indicated they wanted more information regarding what to look for when doing an examination (See Figure 1). While there seemed to

Figure 1

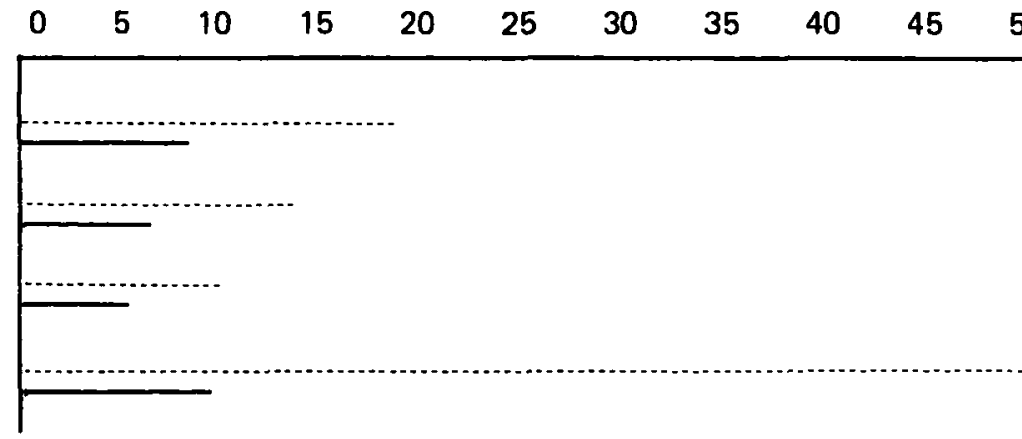


Figure 2

Percentage of students identifying source and preference of source of information about breast self-examination

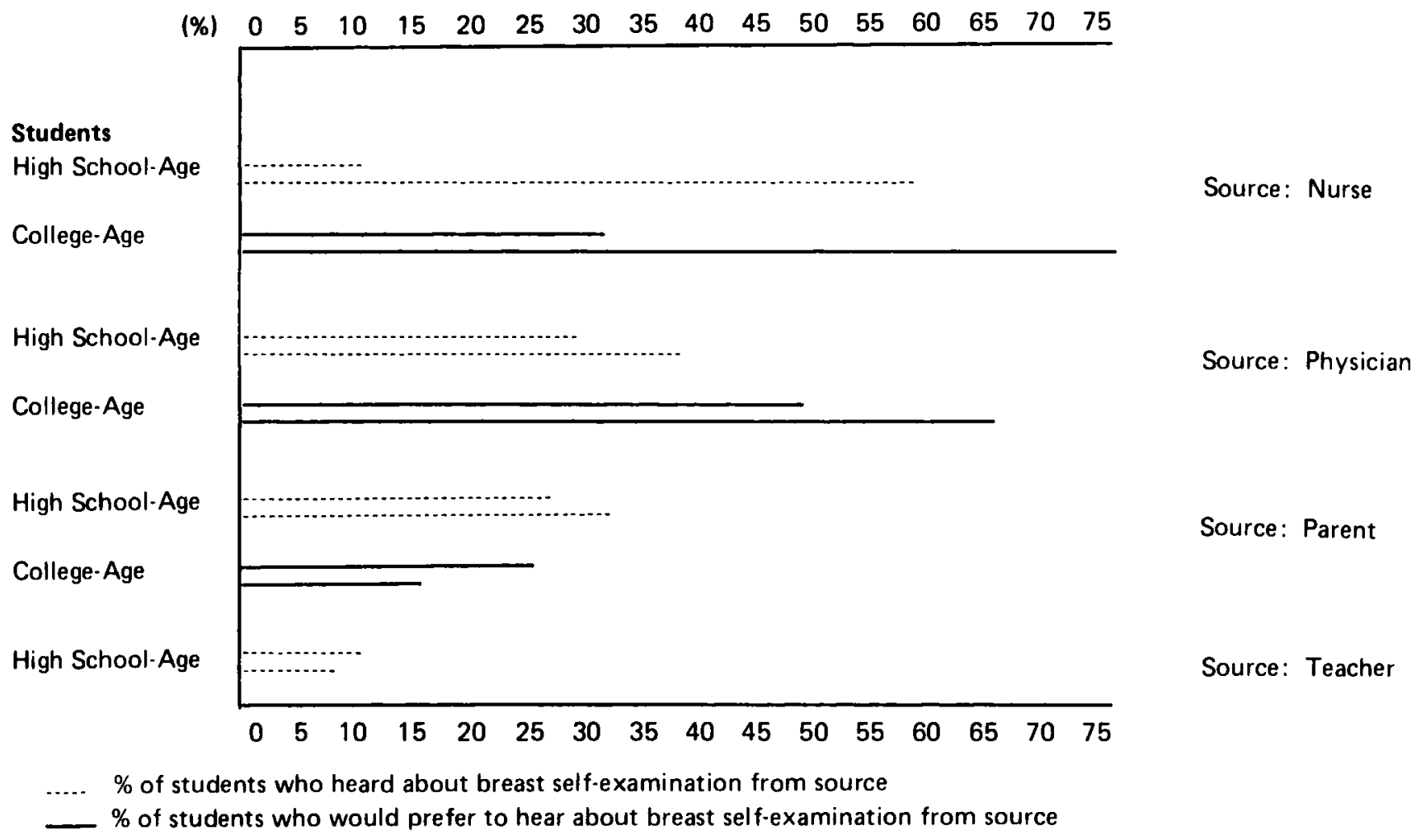

be general understanding of why, when and how to do breast selfexaminations, our sample supports the Gallup Poll that women need specific information of what to look for.

On an importance scale of 1 (least important) to 10 (most important) both groups showed a mean of 8.87 , expressing the view that it is very important to do breast self-examination. Women know it is important, but they lack the specific skill of knowing what is "normal" for them.

Each group was also asked where they had learned about breast self-examination. The majority of both groups learned about this from parents, television, newspapers, pamphlets, or doctors. They heard about this least frequently from nurses and teachers. Twelve percent of the high school-age students and $10 \%$ of those college-age identified this as the first time they had heard about breast self-examination. When asked to name their preferred instructor, $57 \%$ of the high school-age group and $\mathbf{7 5 \%}$ of the college-age group identified the nurse. For those high school-age, the doctor was the second choice, with their parents third, and their teacher the least preferred. Sixty-five percent of the high school-age group and $30 \%$ of the college-age group preferred the teacher to be female while $25 \%$ of the high school-age group and $50 \%$ of the college-age group expressed no sexual preference. The young high school female wants to be taught breast self-examination by a female nurse. This is shown in Figure 2. When asked the preferred age for this skill to be taught, $90 \%$ of the high school-age students and
$80 \%$ of the college-age group expressed the view that breast self-examination should be taught in high school or to high school-age women. This might indicate that parents of high school students would support the placement of breast self-examination in the curriculum.

When asked with whom the high school-age women would be comfortable discussing breast selfexamination, $60 \%$ stated they would be comfortable discussing it with their mothers. We had hoped that we might reach the "high risk" age female through the high school-age population. These findings support this theory. When comparing the "comfort index" with an "intention index," however, we found that only $41 \%$ intended to share this information with their mothers. This was not as high a 
figure as we had hoped. Fortyseven percent of the high schoolage students and $75 \%$ of the college-age students said that they intended to share this information with anyone who was interested. How they would determine who was interested is not answered here.

\section{Setting Up a High School Program}

Program planning for breast selfexamination includes identifying concerns faculty and parents have regarding this material as well as finding the appropriate teacher who is comfortable teaching both men and women.

One concern of faculty and parents might be that high schoolage girls are not the population at risk and therefore not the preferred age for teaching this subject. There are at least three reasons why high school students are the appropriate age for teaching breast self-examination. First, we know that the earlier health habits are established, the more likely they are to be followed through life. Breast self-examination is only useful when the girls have developed breast tissue, however. Most eleventh- and twelfth-graders have developed breast tissue so this age group is probably the best population to reach. Second, there is potential that the high school-age students will talk about this with their mothers, who are in the high risk group and may need more information. Third, we found that the voluntary attendance was higher in the high school-age group than the college-age group (6\% compared with $1.5 \%$ ). We found that high school-age students were more comfortable with learning about breast self-examination than were older women. Women seem to become more uncomfortable about touching themselves as they become older.
Another concern which might be encountered when introducing breast self-examination into the curriculum is finding the time to teach the material. One supporting factor in favor of teaching breast self-examination is the high prevalence of this health problem. Teaching breast self-examination also reduced the anxiety and fear needlessly experienced by many women. Physical education programs often include a section on health. This might be one possible time to teach this. In one high school the students requested that the school newspaper present diagrams of the procedure of breast self-examination. We found that an hour is sufficient to teach this skill in small groups of about 20 students. Additional time should be allowed for individual practice of this skill. We also found that many students were motivated enough to give up a study period in order to gain this knowledge on a voluntary basis.

An opportunity might be provided for the girls to voluntarily inspect and palpate their own breasts in private as well as just being taught the content. Since we know that teaching women about breast self-examination is only the first step, it is also important that they be able to do this on themselves. Hopefully, by having done this on themselves more will continue to do this on a monthly basis.

Men also need to be included in this teaching as many women who discover lumps admit that their boyfriend or husband actually discovered them first. The men included in this study conducted themselves in a mature fashion and were happy to be included in receiving this information.

One of the most important steps in setting up a high school program is the selection of the teacher. The teacher should be carefully selected on the basis of knowledge and comfort level with this material. Some people are uncomfortable with the sexual connotations of touching their own breasts while others are concerned with the unnecessary fear that might result. Another concern is that students will not approach this material in a mature fashion, yet our experience did not support this contention.

The sample high school-age students preferred to be taught breast self-examination by female nurses. Nurses have credibility and studies show that credibility relates postively to the acceptance of the communication. ${ }^{4,5}$ If the teacher is perceived as a trustworthy, reliable expert, the teaching tends to be more effective. ${ }^{4}$

Fear arousal should be avoided when teaching breast self-examination. Research has shown that minimal fear arousal is the most effective method of motivating people toward actual health care practices. $^{5}$ The content should be presented without frightening statistics and without material depicting mastectomy patients. It is well to remember that relating frightening consequences causes people to minimize the importance of these threats. ${ }^{5}$

We would recommend that students be asked to make a public commitment to share what they have learned with others. Though the students were asked to make a written committment to share the information learned, a public verbal committment might have created an even higher motivation level. Research demonstrates that a public, verbal commitment might have created an even higher motivation level and that more often leads to action. ${ }^{4,5}$ 


\section{Evaluation of Teaching}

Evaluation of the teaching is necessary. The questionnaire that was given ${ }^{6}$ included knowledge of the material, more information desired, teacher preference, intention to share, and openended comments. The comments were overwhelmingly positive except for a few students who had experienced cancer with their own families. These students were pessimistic and fatalistic in their attitudes toward cancer. Their comments were strong enough to warrant some counseling on the realities and fallacies surrounding cancer.

It is our hope that school health personnel who read this will consider adding the teaching of breast self-examination to the curriculum. Our study demonstrated that both male and female high school-age students want and can handle this information. As teaching breast selfexamination on the high school level becomes more acceptable and occurs more frequently,

\author{
Elizabeth T. S. Keller, MPH \\ Assistant Professor of Nursing \\ School of Nursing, \\ Public Health Nursing \\ University of Michigan \\ 1021 E. Huron \\ Ann Arbor, MI 48109
}

other female teachers may become more comfortable with this material. When breast self-examination is taught by health teach. ers, students may become more comfortable learning this skill from these teachers and breast self-examination will truly become a permanent part of the high school curriculum.

\section{REFERENCES}

1. American Cancer Society: 75 Cancer Facts and Figures. New York, American Cancer Society Inc, 1974, pp 15-16.

2. Reinhardt A, Quenn M: FamilyCentered Community Nursing: A Soci. ocultural Framework. St. Louis, CV Mosby Co, 1973, p 27.

3. Spradley BW (ed): Contemporary Community Nursing. Boston, Little, Brown and Co, 1975, p 104.

4. Knutson A: The Individual, Society and Health Behavior. New York, Russell Sage Foundation, 1965, pp 466-468.

5. Morrison A, MeIntyre D: Teachers and Teaching. Baltimore, Penguin Books, 1969, pp 166-167.

6. Erickson H: Consumer Knowledge about Breast Self Examination. Unpublished study and questionnaire.

Janne L. R. Dunham, MS
Instructor, Continuing
Education for Nurses
School of Nursing
University of Michigan
1355 Catherine Street
Ann Arbor, MI 48109

\section{Student Evaluation of a Dental Health Program for Third- and Fourth-Grade Students}

The article, "A Dental Health Program," described a program in which each of twelve school districts was aided by a supervising dentist who provided manpower and materials for a class 3 dental inspection, followed lumination. ${ }^{2}$ The plaque control instruction was provided by dental hygienists who were members of the local component dental hygiene society and the toothbrushes were provided by the P.T.A. of each school at a cost of ten cents.*

This annual program serves 80,000 students in public, private, and parochial schools.

A dental quiz was administered by classroom teachers to 1300 third- and fourth-grade students on May 4,1973 . This date was six weeks after the day of inspection and plaque control instruction in the Inglewood (Calif) Unified School District.

The Hawthorne (Calif) School District quizzed the same grades on February 19, 1974, and on March 3, 1975, approximately six weeks following dental inspection and instruction. Each classroom teacher explained each question to the students and aided in the completion of the quiz. The results are shown in Table 1.

Each year, approximately 50\% of the students demonstrate untreated decay. The results, as shown in question 5 , would suggest the program leads to professional dental restorative care. This notion is reinforced by the experience of local charitable clinics and dental practitioners. Since each year $50 \%$ of the students are found to need restorative care, the program has little impact in reducing the prevalence of dental caries. However, it is the opinion of the school nurses of the twelve school districts that demands for emergency dental care have diminished steadily since the annual inspection program began four years ago. The communities served provide water naturally

- See Lion Toothbruah Co advertisement in THE JOURNAL OF SCHOOL HEALTH, November 1975. 